\title{
Depression, antidepressants and driving safety
}

Linda L. Hill ${ }^{1 *}$, Vanessa L. Lauzon ${ }^{2}$, Elise L. Winbrock' ${ }^{1}$ Guohua Li ${ }^{4}$, Stanford Chihuri ${ }^{5}$ and Kelly C. Lee ${ }^{3}$

\begin{abstract}
Background: The purpose of this study was to review the reported associations of depression and antidepressants with motor vehicle crashes.

Purpose: A literature search for material published in the English language between January, 1995, and October, 2015, in bibliographic databases was combined with a search for other relevant material referenced in the retrieved articles.

Methods: Retrieved articles were systematically reviewed for inclusion criteria: 19 epidemiological studies (17 case-control and 2 cohort studies) fulfilled the inclusion criteria by estimating the crash risk associated with depression and/or psychotropic medications in naturalistic settings.

Results: The estimates of the odds ratio (OR) of crash involvement associated with depression ranged from 1.78 to 3.99. All classes of antidepressants were reported to have side effects with the potential to affect driving safety. The majority of studies of antidepressant effects on driving reported an elevated crash risk, and ORs ranged from 1.19 to 2.03 for all crashes, and 3.19 for fatal crashes. In meta-analysis, depression was associated with approximately 2-fold increased crash risk (summary $\mathrm{OR}=1.90 ; 95 \% \mathrm{Cl}, 1.06$ to 3.39), and antidepressants were associated with approximately $40 \%$ increased crash risk (summary $\mathrm{OR}=1.40 ; 95 \% \mathrm{Cl}, 1.18$ to 1.66 ).

Conclusion: Based on the findings of the studies reviewed, depression, antidepressants or the combination of depression and antidepressants may pose a potential hazard to driving safety. More research is needed to understand the individual contributions of depression and the medications used to treat depression.
\end{abstract}

Keywords: Crashes, Driving, Depression, Antidepressants, Intentional crashes

\section{Review}

\section{Background}

Motor vehicles crashes are a leading cause of death in the U.S. with 32,675 fatalities reported in 2014, and an $8 \%$ increase in the first half of 2015 (National Highway Traffic Safety Administration. Data: NHTSA [Internet] 2015). Both medical conditions and medications have the potential to impair the ability to safety operate a motor vehicle (Meuleners et al. 2006; Zuin et al. 2002). The crash risk has been reported to increase with increasing numbers of daily medications (LeRoy \& Morse 2008; Monarrez-Espino et al. 2014). Depression is a highly prevalent and underdiagnosed (Centers for Disease Control and Prevention 2010; Mitchell et al. 2009) condition. It affects nearly $10 \%$ in the adult

\footnotetext{
* Correspondence: Ilhill@ucsd.edu

'Department of Family Medicine and Public Health, San Diego, USA

Full list of author information is available at the end of the article
}

population, and has a lifetime prevalence of approximately 13\% (Hasin et al. 2005; Patten et al. 2006). Psychomotor retardation can be a manifestation of depression and may potentially influence driving safety (Sherwood 1995; Austin et al. 2001; Bulmash et al. 2006). Antidepressants as a group are the second most commonly prescribed drug classes (Aitken 2014). Antidepressants may alleviate the symptoms of depression, but they may be associated with side effects that could impair driving (Sherwood 1995).

The purpose of this study was to review the reported effects of depression and antidepressants on motor vehicle crash risk. The diagnosis and treatment of depression has changed significantly over the last 40 years. This paper includes epidemiologic studies conducted in the last 20 years since the publication of the Diagnostic and Statistical Manual of Mental Disorders, $4^{\text {th }}$ Edition 
(DSM-IV) in 1994. Experimental studies, mainly using driving simulators, were not included in this review.

\section{Methods \\ Eligibility}

Studies were included if they (National Highway Traffic Safety Administration. Data: NHTSA [Internet] 2015) examined the association between depression or antidepressant use and motor vehicle crash risk; (Meuleners et al. 2006) used an epidemiologic design (e.g., cohort, case control, and case-crossover), and (Zuin et al. 2002) were published in English between January, 1995, and October, 2015. Cross-sectional studies, qualitative studies, reviews, commentaries, opinion pieces, and magazine articles were excluded. In this review, depression was ascertained through questionnaires such as the Geriatric Depression Scale (GDP), General Health Questionnaire (GHQ) or their modified versions, as well as interviews and claims-based databases. Antidepressants included classes of medications prescribed for the treatment of depression such as tricyclics (e.g. amitriptyline, imipramine), monoamine oxidase inhibitors (MAOI) (, e.g. phenelzine, tranylcypromine), selective serotonin reuptake inhibitors (SSRI) (, e.g.citalopram, escitalopram), serotonin-norepinephrine reuptake inhibitors (SNRI )(e.g.venlafaxine, duloxetine), and atypicals (e.g. bupropion, mirtazapine).

\section{Search Strategy and Data Extraction}

Relevant articles were identified through a comprehensive search of the research literature. Electronic database searches included PubMed (1995-October, 2015), Medline Plus (1995-October, 2015), Google Scholar (1995-October, 2015), Ingenta Connect (1995-October, 2015), and grey literature databases. One author (LH) conducted the initial search and screened study titles and abstracts using the inclusion and exclusion criteria. Other authors (SC, KL, EW) independently searched for relevant studies and collected and recorded data used to estimate odds ratios from eligible studies. For each included study, information on author, year of publication, study sample, study design, country, study period, and findings were noted.

\section{Quality Assessment and Data Analysis}

All studies that met the inclusion criteria were assessed for quality using the Newcastle-Ottawa Scale (NOS) (Wells et al. 2015) as recommended by the Cochrane Collaboration on bias assessment (Higgins \& Green S. Cochrane Handbook for Systematic Reviews of Interventions Version 5.1.0 [updated March 2011). For the study designs included in this study, the best possible score is 9. Better quality studies will have higher scores. Heterogeneity was assessed using the $\mathrm{Q}$ and $\mathrm{I}^{2}$ tests, with $\mathrm{P} \leq .05$ and $\mathrm{I}^{2}>0.5$ considered homogenous. Funnel plots were used to assess publication bias. Data abstracted from each study were entered in the Comprehensive Meta-Analysis software (Borenstein et al. 2005) to compute the individual odds ratios and a summary odds ratio for each of the two analyses. A fixed effects model was used unless heterogeneity was present, in which case, a random-effects model would be preferred. Two forest plots were created; one to show the distribution of the effect of depression on car crash risk (Fig. 1) and another one to show the distribution of the effect of antidepressant use on car crash risk (Fig. 2).

\section{Results}

The effect of depression on driving and crashes

Seven studies investigating the effect of depression on driving met the inclusion criteria (Table 1). Rainio et al (Rainio et al. 2007) conducted a retrospective review of crashes in 2001 and 2002, using interviews of police, surviving drivers, and family members, medical records, and autopsy reports. A physician on the team made the determination of the presence of depression. This Finnish study used the reports of the road crash investigation teams which investigate every fatal crash in Finland. Of the 640 crash deaths analyzed, 390 were

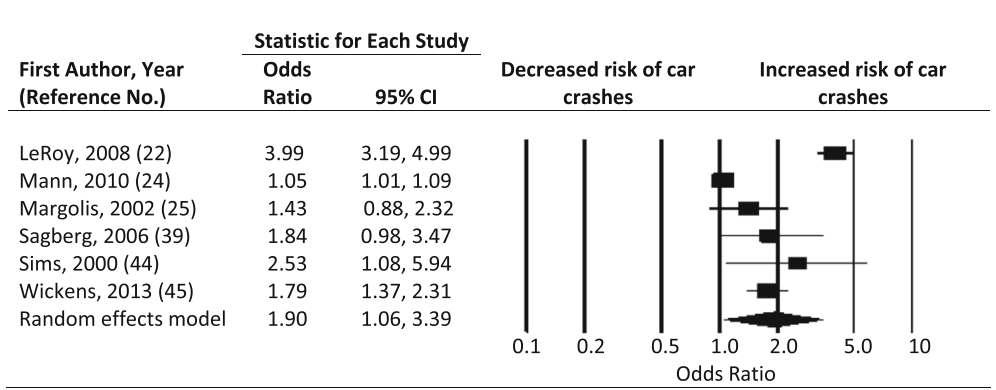

Fig. 1 Forest plot, summary odd ratio and $95 \%$ confidence of association of risk of car crashes with depression. The summary odds ratio is indicated by the diamond. Horizontal bars indicate the $95 \%$ confidence intervals 


\begin{tabular}{|c|c|c|c|c|}
\hline \multirow[b]{2}{*}{$\begin{array}{l}\text { First Author, Year } \\
\text { (Reference No.) }\end{array}$} & \multicolumn{2}{|c|}{$\begin{array}{l}\text { Statistic for Each } \\
\text { Study }\end{array}$} & \multirow[b]{2}{*}{$\begin{array}{l}\text { Decreased risk of car } \\
\text { crashes }\end{array}$} & \multirow[b]{2}{*}{$\begin{array}{l}\text { Increased risk of car } \\
\text { crashes }\end{array}$} \\
\hline & $\begin{array}{l}\text { Odds } \\
\text { Ratio }\end{array}$ & $95 \% \mathrm{Cl}$ & & \\
\hline Barbone, 1998 (6) & 0.85 & $0.55,1.32$ & | & \\
\hline Gibson, 2008 (12) & 0.96 & $0.85,1.09$ & & \\
\hline Hooper, 2010 (18) & 3.19 & $1.01,10.07$ & & \\
\hline LeRoy, 2008 (22) & 1.90 & $1.49,2.43$ & & \\
\hline Ravera, 2011 (38) & 2.03 & $1.31,3.14$ & & \\
\hline Sagberg, 2006 (39) & 1.79 & $1.19,2.70$ & & \\
\hline Orriols, 2012 (32) & 1.34 & $1.22,1.47$ & & \\
\hline Orriols, 2013 (33) & 1.42 & $1.30,1.55$ & & $\bar{\square}$ \\
\hline Fixed effects model & 1.36 & $1.28,1.43$ & & 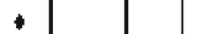 \\
\hline Random effects model & 1.40 & $1.18,1.66$ & & \\
\hline
\end{tabular}

Fig. 2 Forest plot, summary odd ratio and 95\% confidence of association of risk of car crashes with anti-depressants. The summary odds ratio is indicated by the diamond. Horizontal bars indicate the $95 \%$ confidence intervals

drivers considered to be at fault. Of these $390,6.4 \%$ had depression, while one non-fault driver and none of the non-fault passengers had depression (Rainio et al. 2007). No medication data were included in the analysis. Sagberg (Sagberg 2006) used self-report questionnaires from 4448 crash-involved drivers in Norway and found an OR of 2.43 in persons reporting depression. Though antidepressants were included, the relationship between antidepressants and depression was not included in the analysis. Mann et al (Mann et al. 2010) did a crosssectional telephone survey of adults in Ontario, Canada aged 18 and older. Depression and anxiety were determined using two subscales of the 12-item General Health Questionnaire: Depression-anxiety and social functioning. With a sample of 4935 adults, Mann et al (Mann et al. 2010) found the odds of crash involvement increased significantly with an increase in the anxiety/ depression score, with a five percent increase in the risk of crash involvement for every unit of anxiety/depression increase (95\% CI, 1.01 to 1.09). Medications for depression were not included in the study. Wickens et al (Wickens et al. 2013), also with an Ontario sample of 12,830 , studied self-reported anxiety and mood disorders, queried via telephone survey, and found an increase in crashes $(\mathrm{OR}=1.78 ; 95 \% \mathrm{CI}, 1.37$ to 2.31 ). There was no report of antidepressant use. Sims et al (Sims et al. 2000), in a prospective analysis of 174 older adults, used baseline and one year follow-up inperson assessments. They found that a Geriatric Depression Scale score $\geq 16$ was associated with an increased crash rate $(\mathrm{RR}=2.53 ; 95 \% \mathrm{CI}, 1.08$ to 5.95$)$. While antidepressant use was assessed, the relationship between depression, antidepressants and crashes was not reported, and in this study the relationship between antidepressant use and crashes was not significant. LeRoy (LeRoy \& Morse 2008) found an OR of 3.99 for crash risk with depression in a case control study of 81,408 cases and 244,224 controls (95\%
CI, 3.19 to 4.99) using claims-based population data. Another study of older adults (Margolis (Margolis et al. 2002)), using the Geriatric Depression Scale, included depression in their analysis and found no association; however, this study was small, with a low prevalence of depression in the study population (Margolis et al. 2002; McGwin et al. 2000).

\section{The effect of antidepressants on driving}

Ten studies (Table 2) meeting inclusion criteria evaluated the relationship between antidepressants and motor vehicle crashes. Several studies have used populationbased data sets to assess the risk of antidepressants and driving (National Highway Traffic Safety Administration. Data: NHTSA [Internet] 2015; Meuleners et al. 2006; Aitken 2014; Bramness et al. 2008; Barbone et al. 1998; Ravera et al. 2011; Gibson et al. 2009; Lam et al. 2005; Greenblatt et al. 1999). Hooper et al (Hooper et al. 2010) retrospectively studied a U.S. active duty military population between 2002-2006, using an integrated health systems database, and found an adjusted OR of 3.19 for the effect of antidepressants on crash risk (95\% CI, 1.01 to 10.07). Depression was not assessed. Orriols et al (Orriols et al. 2012) did a case-crossover analysis of 72,685 drivers in France using the national health care insurance database and the national police database and found an OR of 1.34 for crash and prescription of antidepressants as a class (95\% CI, 1.22 to 1.47). SSRIs (OR $=1.30 ; 95 \% \mathrm{CI}, 1.16$ to 1.46$)$, SNRIs $(\mathrm{OR}=1.51 ; 95 \% \mathrm{CI}$, 1.25 to 1.84$)$, and other antidepressants $(\mathrm{OR}=1.30 ; 95 \%$ CI, 1.01 to 1.67 ) also had a significant association with increased risk of crash. In a different analysis, Orriols et al (Orriols et al. 2013) studied 109,406 older drivers aged 66-84 years in Quebec, Canada, using provincial police and health databases. They found that $20 \%$ had at least one prescription of an antidepressant during the study period, and $2.7 \%$ were exposed to antidepressants on the day of the crash $(\mathrm{OR}=1.19 ; 95 \% \mathrm{CI}, 0.94$ to 1.51$)$. 


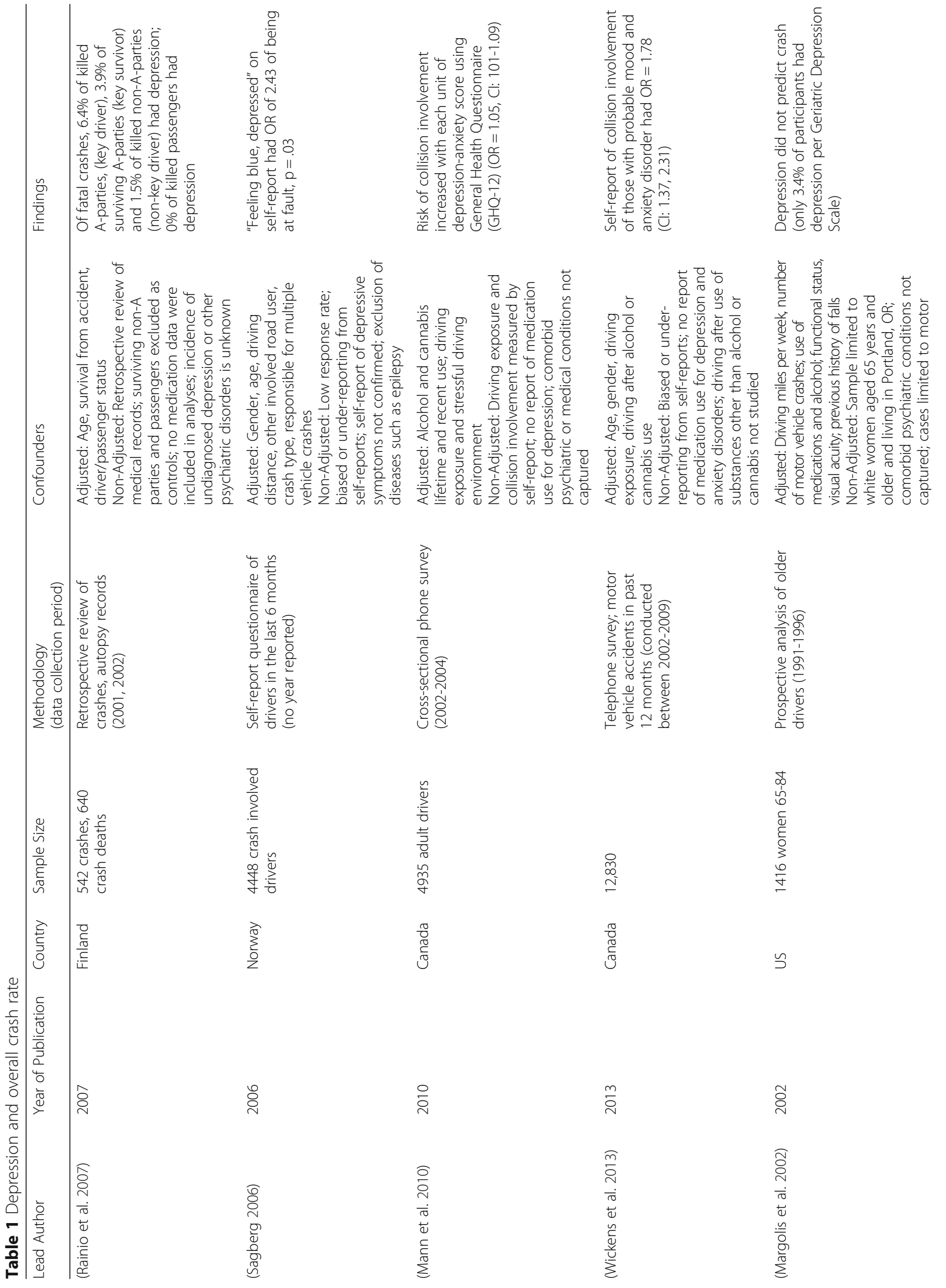




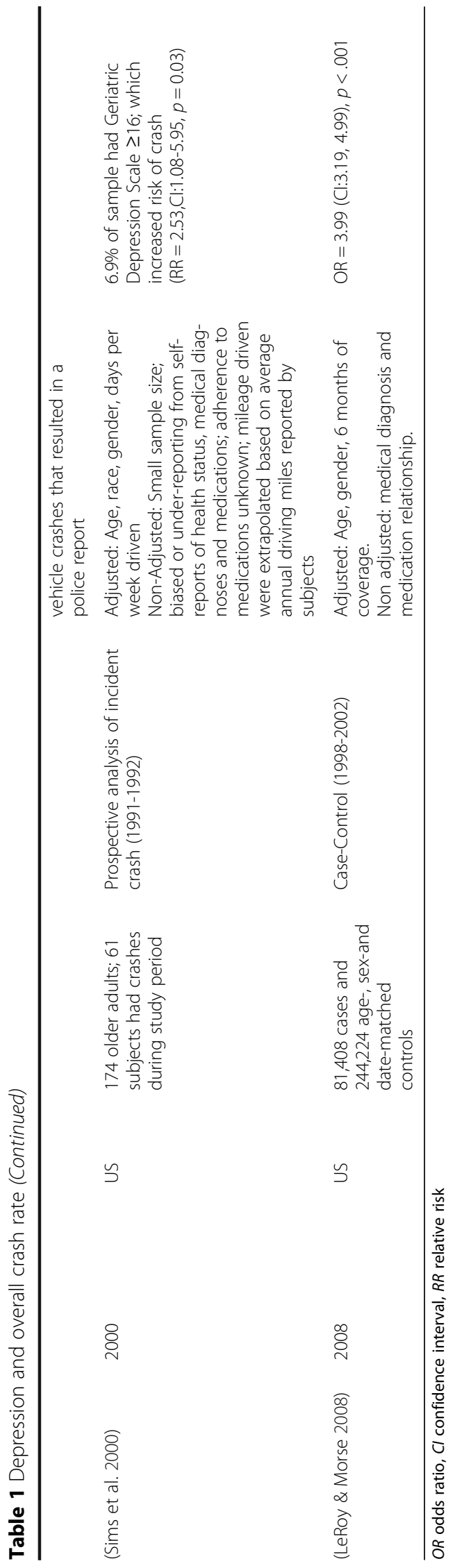




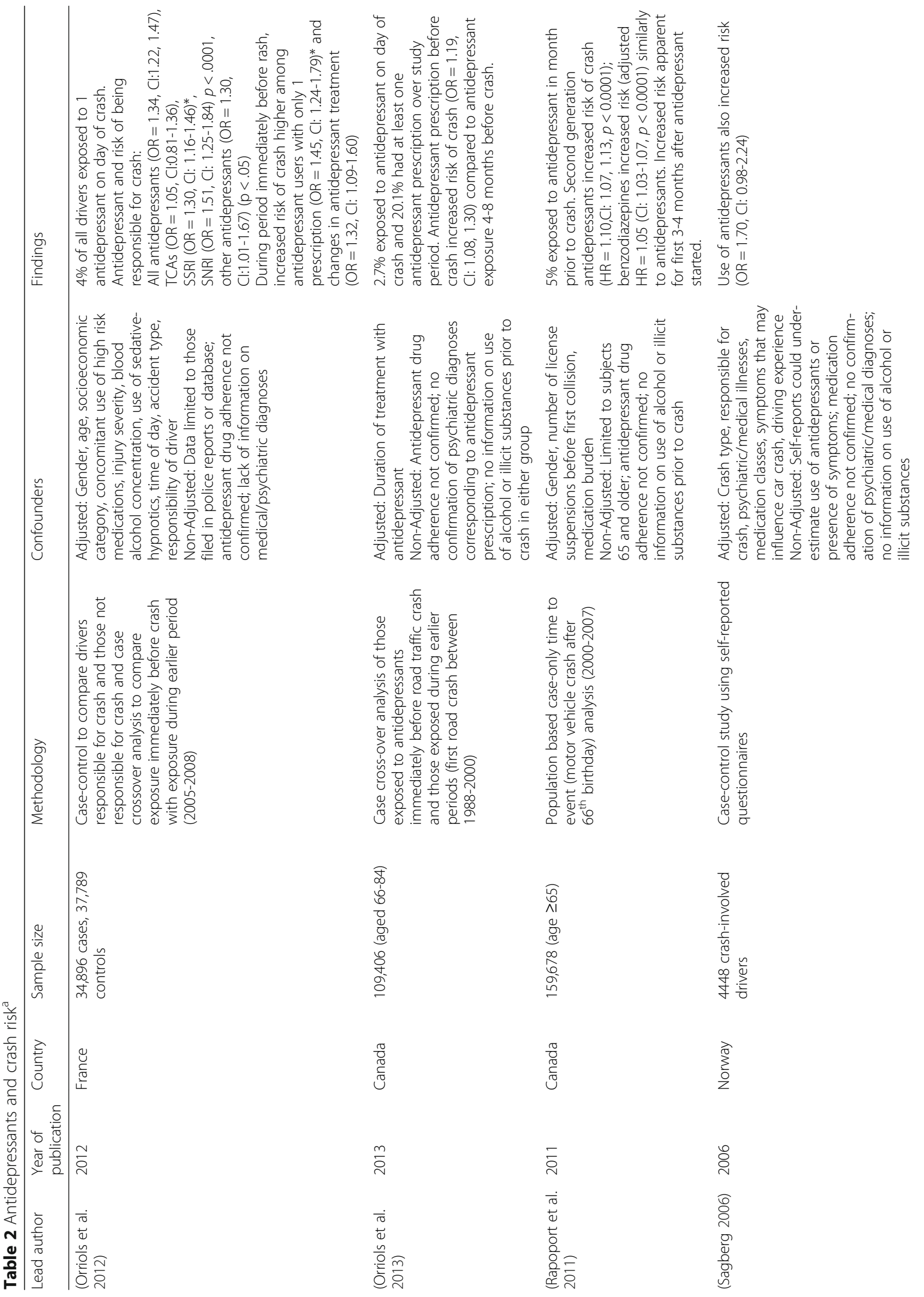


Hill et al. Injury Epidemiology (2017) 4:10

Page 7 of 10

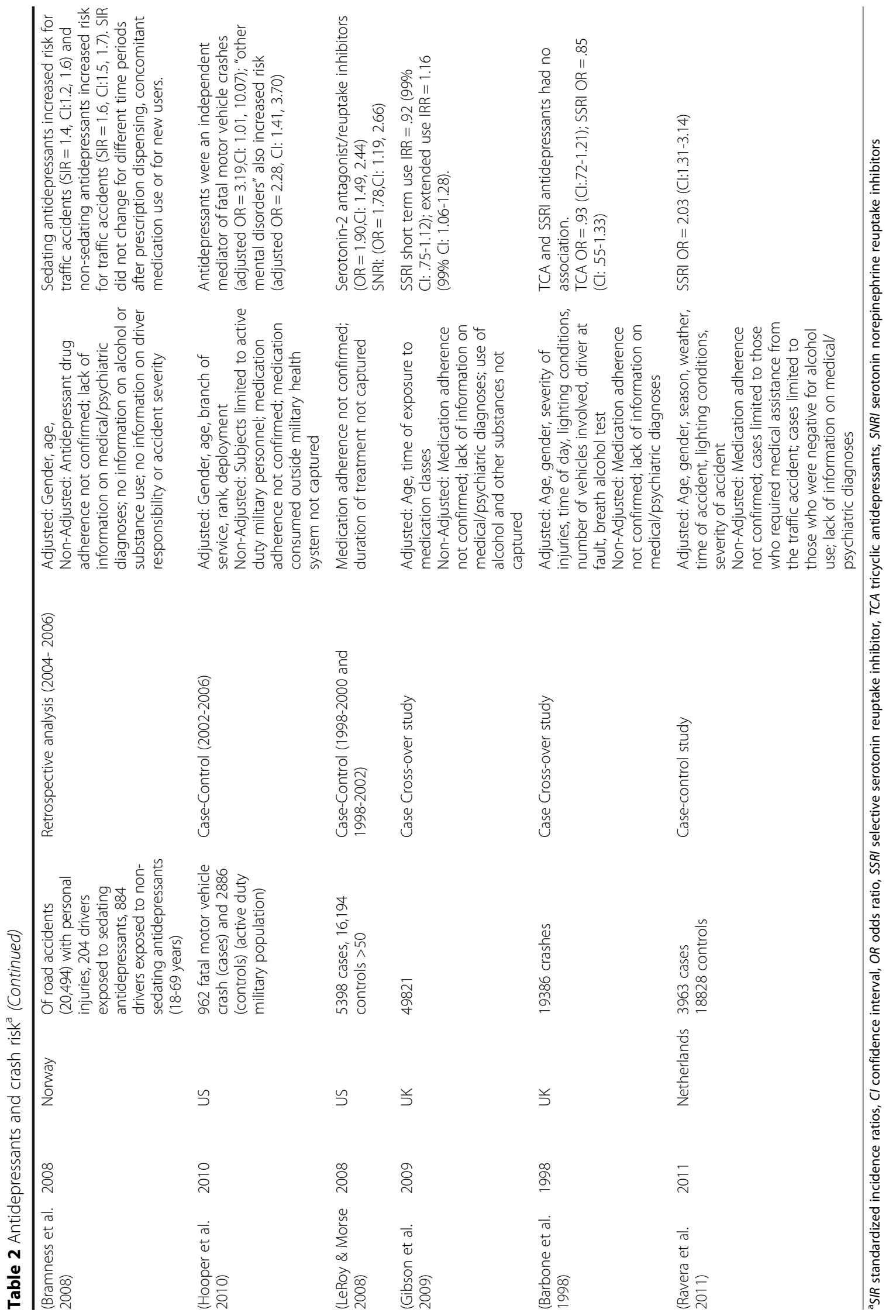


Neither of the studies by Orriols included data on depression. Rapaport (Rapoport et al. 2011) did a case-only time to event analysis in 159,678 persons in Ontario, also using provincial databases, and found that SSRI and SNRI antidepressants were associated with at-fault crashes alone (HR $=1.10$; $95 \% \mathrm{CI}, 1.09$ to 1.13$)$, in combination with a benzodiazepine (adjusted $\mathrm{HR}=1.23$; $95 \%$ CI, 1.17 to 1.28 ), and with an anticholinergic medication (adjusted HR $=1.63$; 95\% CI, 1.57 to 1.69). The period within the first 3-4 months of antidepressant initiation also was associated with increased risk of crash (Rapoport et al. 2011). Bramness (Bramness et al. 2008), using national databases, found non-sedating antidepressants increased the risk for traffic crashes $(\mathrm{SIR}=1.6 ; 95 \% \mathrm{CI}, 1.5$ to 1.7$)$ more than sedating antidepressants (SIR $=1.4 ; 95 \% \mathrm{CI}, 1.2$ to 1.6). Neither Rapaport nor Bramness include depression as a variable. Sagberg (Sagberg 2006), in a Norwegian study of 4,448 crash involved drivers, found the self-reported use of antidepressants had an adjusted OR for crash of 1.70 (95\% CI, 0.98 to 2.24). While this study, and the following two studies (LeRoy and Sims) included both depression and anti-depressants, the relationship between the two variables was not assessed. LeRoy (LeRoy \& Morse 2008), in a US-based case-control study of 5,398 cases and 16, 194 controls, using national survey and also claims-based databases, found that serotonin-2 antagonist/reuptake inhibitors had an OR for crash of 1.90 (95\% CI, 1.49 to 2.44). Barbone (Barbone et al. 1998), in a case crossover study in the UK, used a local prescription database and found no association between crash and tricyclic or SSRI antidepressants in the 1998 study of 19,386 crashes. Ravera (Ravera et al. 2011) in the Netherlands study of 3,963 cases and 18,828 controls used three existing Dutch population-based databases and found an OR of crash with SSRI of 2.03 (95\% CI, 1.31 to 3.14). Gibson (Gibson et al. 2009), using a primary care database, found that SSRI had no effect in the short term (IRR $=.92 ; 99 \% \mathrm{CI}, 0.75$ to 1.12 ), but had a small increase in the risk of crash with extended use $(\mathrm{IRR}=1.16 ; 99 \% \mathrm{CI}, 1.06$ to 1.28$)$ in a case crossover study of 49,821 crashes. None of these three studies included depression as a variable.

\section{Meta-analysis: Depression and car crash risk}

Three cohort (Mann et. al (Mann et al. 2010); Margolis et. al (Margolis et al. 2002); Sims et.al (Sims et al. 2000)) and three case control studies (LeRoy et. al (LeRoy \& Morse 2008); Sagberg (Sagberg 2006); Wickens et. al (Wickens et al. 2013)) that examined the association between depression and car crash risk were included in the quantitative meta-analysis (Table 1). One study (Rainio et. al (Rainio et al. 2007)) was excluded from the depression meta-analysis because it assessed aggregate data on crashes, crash deaths, and depression. Effect estimates showed some heterogeneity $(\mathrm{Q}=153.741, \mathrm{df}=5$, $\left.P=0.000 ; \mathrm{I}^{2}=96.748\right)$, hence a random effects model was used. A funnel plot from the six studies did not indicate any major publication bias. Pooled data from the six studies indicate that depression nearly doubles the risk of involvement in a car crash (summary $\mathrm{OR}=1.90$; 95\% CI,1.06 to 3.39) (Fig. 1).

\section{Meta-analysis: Antidepressant use and car crash risk}

Three case-crossover (Barbone et.al (Barbone et al. 1998), Gibson et. al (Gibson et al. 2009), Orriols et. al (Orriols et al. 2013)) and five case control studies (Hooper et. al (Hooper et al. 2010), LeRoy et. al (LeRoy \& Morse 2008), Ravera et.al (Ravera et al. 2011), Sagberg et.al (Sagberg 2006), Orriols et. al (Orriols et al. 2012)) were included in the quantitative meta-analysis on antidepressant use and crash risk (Table 2). Two studies (Bramness et. al (Bramness et al. 2008), Rapoport et. al (Rapoport et al. 2011)) were excluded from the antidepressant use meta-analysis because event data could not be extracted. Effect estimates showed some heterogeneity $\left(\mathrm{Q}=47.337, \mathrm{df}=7, \mathrm{P}=0.000 ; \mathrm{I}^{2}=85.212\right)$, hence a random effects model was used. The random effects and the fixed effects model estimates were close. A funnel plot from the six studies did not indicate any major publication bias. Pooled data from the eight studies show that antidepressant use may increase the risk of car crash involvement by $40 \%$ (summary OR $=1.40$; $95 \%$ CI, 1.18 to 1.66) (Fig. 2).

\section{Discussion}

Depression and antidepressants have mental and physical effects with the potential to adversely affect the ability to operate a motor vehicle. Depression, in addition to psychomotor retardation, is often associated with suicidal ideation and intent, increasing the potential for both unintentional and self-harm related motor vehicle crashes (Lam et al. 2005). The studies reviewed, conducted mainly in developed countries, found associations between depression and crashes. Though estimates are hampered by the variation in study population and study design, depression was generally found to approximately double the risk of crash risk.

Antidepressants have numerous side effects that include drowsiness, hypotension, suicidal ideation, dizziness, decreased seizure threshold, nausea, and anxiety. These may individually and combined have the potential to interfere with driving abilities. Studies of the effects of antidepressants as a class and driving found a modest increase in crash risk, with OR ranging from 1.19 to 1.90 for crashes, and 3.19 for fatal crashes. The effect varied by type of antidepressant, with significant variation 
between studies, but averaged about 1.4 times the crash risk in meta-analysis.

Antidepressants have potentially conflicting contributions to motor vehicle crashes in relieving the effects of depression and suicide while posing side effects that may affect driving. While the benefits of antidepressants outweigh their potential risks, prospective studies are needed to better understand the risk of antidepressants and depression on motor vehicle crashes. Of the seven studies included in this analysis assessing the effects of depression, only three (Sagberg, LeRoy and Sims) included information on antidepressants. However, no comparison of depression scores, medications use, and crash risk in given individuals was reported. Equally, the studies of the effects of antidepressants did not assess the current or past levels of depression. Future studies are needed to control for these interactions.

In addition to the effects of the drugs when taken alone, antidepressants can interact with numerous classes of medications primarily due to their inhibition of metablism of other drugs that are cleared through the cytochrome P-450 system of enzymes. Drug interactions may be especially important in impairing attention and cognition when antidepressants are combined with drugs that also have sedative properties, such as benzodiazepines and tricyclic antidepressants (TCAs). Among antidepressants and their active metabolites, norfluoxetine and fluvoxamine have significant inhibitory effects on CYP 3A4 isoenzyme, which is the most abundant CYP enzyme found in the human body (Greenblatt et al. 1999). Fluoxetine and fluvoxamine have been reported to reduce metabolism of multiple drugs, specifically the triazolobenzodiazepines (triazolam, alprazolam, and midazolam). By blocking the metabolism of these benzodiazepines, the serum concentrations of the benzodiazepines may increase and have increased side effects (i.e. increased sedation, dizziness, impaired cognition). It should be recognized that although in vitro affinities of antidepressants for the respective isoenzymes can be very helpful for predicting potentially dangerous drug combinations, there is wide variability between patients and their susceptibility for these interactions. Much of this variability can be attributed to genetic polymorphisms.

The strengths of this review include that 17 of the studies reported used large population-based databases, and 14 included detailed crash analysis, increasing the validity of their findings. Also included were studies from across a number of developed countries, with welldesigned studies that met the inclusion criteria. The studies included in this review have several limitations. The criteria for determination of depression ranged from self-report to claims-based diagnostic codes. In determining the effects of depression and antidepressants, it is difficult to distinguish effects of depression from effects of drugs. The distinction is hampered by the retrospective methodology of the majority of the studies. Additionally, antidepressants are often prescribed with other psychotropic medications, increasing the potential for crashes due to both drugs, as has been demonstrated in several studies (Rapoport et al. 2011).

Due to the limitation of these studies, the extent to which antidepressants mitigate the effects of depression remains unknown. However, the larger association of depression with crash risk, vs. the use of antidepressants, suggests that treatment of depression is likely to reduce the risk. In the management of depression the risk-benefit ratio fo treatment should be considered, as well as the side effect profile when medications are being considered.

\section{Conclusions}

Based on the reports of the studies included in this analysis, depression and antidepressants pose a potential hazard to driving safety. Physicians and other health providers, including pharmacists, should recognize the inherent risks of both the disorder and medications on driving and educate their patients accordingly. More research is needed to understand the individual contributions of depression versus the medications used to treat depression and to identify strategies to mitigate the effect of both on driving safety.

\section{Abbreviations \\ Cl: Confidence interval; DSM-IV: Diagnostic and Statistical Manual of Mental Disorders; GDP: Geriatric Depression Scale; GHQ: General Health \\ Questionnaire; MAOI: Monoamine oxidase inhibitors; OR: Odds ratio; \\ SNRI: Serotonin-norepinephrine reuptake inhibitors; SSRI: Selective serotonin reuptake inhibitor; TCA: Tricyclic antidepressants}

\section{Acknowledgements}

The authors are thankful to the team at the AAA LongROAD study for their contributions.

\section{Funding}

This research was supported in part by the AAA Foundation for Traffic Safety's Longitudinal Research on Aging Drivers (LongROAD) Project and by the National Center for Injury Prevention and Control of the Centers for Disease Control and Prevention (grant 1 R49 CE002096).

\section{Authors' Contributions}

$\mathrm{H}$ : literature review, analysis and interpretation of the studies, drafting of the manuscript; critical revision. L: data acquisition, analysis and interpretation, critical revision. L and W: literature review, interpretation of the studies, critical revision. $L$ and $C$ : data analysis, interpretation and critical revision, and lead on the meta-analysis. All authors read and approved the final manuscript.

\section{Author's Information}

$\mathrm{LH}$ is a family medicine clinician, Professor of Family Medicine and Public Health and director of the Training, Research and Education for Driving Safety Program (TREDS) at the University of California, San Diego (UC San Diego). VL is a Clinical Psychiatrist within the Department of Psychiatry at UC San Diego. EW is a Program Coordinator within the Department of Family Medicine and Public Health and public health research associate at UC San Diego. GL is an epidemiologist, the Director of the Center for Injury Epidemiology and Prevention, the Director of the Department of

Epidemiology at the Mailman School of Public Health and the Director of the Center for Health Policy and Outcomes in Anesthesia and Critical care at Columbia University. SC is an epidemiologist and biostatistician at Columbia 
University. KL is a Board-Certified Psychiatric Pharmacist, an Associate Professor of Clinical Pharmacy and Associate Dean for Assessment and Accreditation.

\section{Competing interest}

The authors declare that they have no competing interests.

\section{Previous Presentation}

Presented in poster format at the "Preventive Medicine 2016" annual meeting hosted by the American College of Preventive Medicine on February 25, 2016 in Crystal City, VA.

\section{Role of sponsors}

The contents of the manuscript are the sole responsibility of the authors and do not necessarily reflect the official views of the funding agencies.

\section{Publisher's Note}

Springer Nature remains neutral with regard to jurisdictional claims in published maps and institutional affiliations.

\section{Author details}

${ }^{1}$ Department of Family Medicine and Public Health, San Diego, USA. ${ }^{2}$ Department of Psychiatry, San Diego, USA. ${ }^{3}$ Skaggs School of Pharmacy and Pharmaceutical Sciences, University of California, 9500 Gilman Drive, La Jolla, San Diego, CA 92093, USA. ${ }^{4}$ Department of Epidemiology, Mailman School of Public Health, New York, USA. ${ }^{5}$ Center for Injury Epidemiology and Prevention, Columbia University Medical Center, Columbia University, 722 West 168th Street, New York, NY 10032, USA

Received: 17 November 2016 Accepted: 10 March 2017

Published online: 03 April 2017

\section{References}

Aitken M. Medicine use and shifting costs of healthcare: a review of the use of medicines in the United States in 2013. 2014.

Austin MP, Mitchell P, Goodwin GM. Cognitive deficits in depression: possible implications for functional neuropathology. Br J Psychiatry. 2001;178:200-6. Available from: http://bjp.rcpsych.org/cgi/content/abstract/178/3/200.

Barbone F, McMahon AD, Davey PG, Morris AD, Reid IC, McDevitt DG, et al. Association of road-traffic accidents with benzodiazepine use. Lancet. 1998; 352:1331-6. Available from: http://www.thelancet.com/journals/lancet/article/ PIIS0140-6736(98)04087-2/abstract.

Borenstein M, Hedges L, Higgins J. Comprehensive Meta-Analysis. Engelwood: Biostat; 2005.

Bramness JG, Skurtveit S, Neutel Cl, Engeland A. Minor increase in risk of road traffic accidents after prescriptions of antidepressants: A study of population registry data in Norway. J Clin Psychiatry. 2008;69(7):1099-103.

Bulmash EL, Moller HJ, Kayumov L, Shen J, Wang X, Shapiro CM. Psychomotor disturbance in depression: assessment using a driving simulator paradigm. $J$ Affect Disord. 2006;93(1-3):213-8. [cited 2016 Jan 6] Available from: http:// www.jad-journal.com/article/S0165-0327(06)00035-8/abstract.

Centers for Disease Control and Prevention. Current Depression Among Adults United States, 2006 and 2008. Morb Mortal Wkly Rep. 2010;59(38):1229-58.

Gibson JE, Hubbard RB, Smith CJP, Tata $\sqcup$, Britton JR, Fogarty A, Gibson JE, Hubbard RB, Smith CJP, Tata $\sqcup$, Britton JR, Fogarty AW. Use of Self-controlled Analytical Techniques to Assess the Association Between Use of Prescription Medications and the Risk of Motor Vehicle Crashes. Am J Epidemiol. 2009;169(1):761-8. Available from: http://aje.oxfordjournals.org/cgi/doi/10.1093/aje/kwn364.

Greenblatt D, von Moltke LL, Harmatz JS, Shader RI. Human Cytochromes and Some Newer Antidepressants: Kinetics, Metabolism, and Drug Interactions. [Internet]. J Clin Psychopharmacol. 1999; p. 23S-35S. [cited 2016 Jan 14] Available from: http://journals.Iww.com/psychopharmacology/Abstract/1999/ 10001/Human_Cytochromes_and_Some_Newer_Antidepressants_3.aspx

Hasin DS, Goodwin RD, Stinson FS, Grant BF. Epidemiology of major depressive disorder: Results from the national epidemiologic survey on alcoholism and related conditions. Arch Gen Psychiatry. 2005;62(10):1097-106. Available from: http://jamanetwork.com/journals/jamapsychiatry/fullarticle/208965.

Higgins J, Green S. Cochrane Handbook for Systematic Reviews of Interventions Version 5.1.0 [updated March 2011]. Cochrane Collab [Internet]. 2011; Available from. www.cochrane-handbook.org.

Hooper TI, DeBakey SF, Pearse L, Pratt S, Hoffman KJ. The use of electronic pharmacy data to investigate prescribed medications and fatal motor vehicle crashes in a military population, 2002-2006. Accid Anal Prev. 2010;42:261-8. Available from: http://www.sciencedirect.com/science/article/pii/S0001457509002097.

Lam LT, Norton R, Connor J, Ameratunga S. Suicidal ideation, antidepressive medication and car crash injury. Accid Anal Prev. 2005;37:335-9. Available from: http://www.sciencedirect.com/science/article/pii/S0001457504000983.

LeRoy AA, Morse ML. Multiple Medications and Vehicle Crashes: Analysis of Databases. Traffic Safety Facts\rTraffic Tech - Technology Transfer Series. 2008.

Mann RE, Asbridge M, Stoduto G, Smart RG, Goldbloom DS, Vingilis ER, et al. Psychological distress and collision involvement among adult drivers. Stress Heal. 2010;26(August 2009):127-34. Available from: http://onlinelibrary.wiley.com/doi/10. 1002/smi.1274/abstract;jsessionid=5D4C49D63A3D7412DEF6622F6D9B0B0B.f04t02.

Margolis KL, Kerani RP, McGovern P, Songer T, Cauley JA, Ensrud KE. Risk factors for motor vehicle crashes in older women. J Gerontol A Biol Sci Med Sci. 2002;57(3):M186-91.

McGwin G, Sims RV, Pulley L, Roseman JM. Relations among chronic medical conditions, medications, and automobile crashes in the elderly: a populationbased case-control study. Am J Epidemiol. 2000;152(5):424-31. Available from: http://www.ncbi.nlm.nih.gov/pubmed/10981455.

Meuleners LB, Harding A, Lee AH, Legge M. Fragility and crash over-representation among older drivers in Western Australia. Accid Anal Prev. 2006;38:1006-10.

Mitchell AJ, Vaze A, Rao S. Clinical diagnosis of depression in primary care: a meta-analysis. Lancet. 2009;374(9690):609-19. Elsevier Ltd. Available from: http://dx.doi.org/10.1016/S0140-6736(09)60879-5

Monarrez-Espino J, Laflamme L, Elling B, Moller J. Number of medications and road traffic crashes in senior Swedish drivers: a population-based matched case-control study. Inj Prev. 2014;20:81-7. Available from: http:// injuryprevention.bmj.com/content/20/2/81.

National Highway Traffic Safety Administration. Data: NHTSA [Internet]. 2015 [cited 2015 Jan 1]. Available from. https://crashstats.nhtsa.dot.gov/?_ga=1. 72979219.1691870535.1482438426\#/PublicationList/51

Orriols L, Queinec R, Philip P, Gadegbeku B, Delorme B, Moore N, et al. Risk of Injurious Road Traffic Crash After Prescription of Antidepressants. J Clin Psychiatry. 2012;73(8):1088-94. [cited 2015 Oct 15] Available from: http:// www.ncbi.nlm.nih.gov/pubmed/22967773.

Orriols L, Wilchesky M, Lagarde E, Suissa S. Prescription of antidepressants and the risk of road traffic crash in the elderly: a case-crossover study. Br J Clin Pharmacol. 2013;76:810-5. Available from: http://doi.wiley.com/10.1111/bcp.12090.

Patten SB, Williams JVA, Currie S, Wang JL, Maxwell C, Beck C, et al. Descriptive epidemiology of major depression in Canada. Can J Psychiatry. 2006;51(2):84-90.

Rainio J, Sulander P, Hantula L, Nuutinen J, Karkola K. Diseases and Motor Vehicle Fatalities in Finland in 2001 and 2002. Traffic Inj Prev. 2007;8(October):321-8. Available from: http://www.tandfonline.com/doi/abs/10.1080/15389580601118862.

Rapoport MJ, Zagorski B, Seitz D, Herrmann N, Molnar F, Redelmeier DA. At-Fault Motor Vehicle Crash Risk in Elderly Patients Treated With Antidepressants. Am J Geriatr Psychiatry. 2011;19(December):998-1006. Available from: https:// www.ncbi.nlm.nih.gov/pubmed/22123273.

Ravera S, van Rein N, de Gier JJ, de Jong-van den Berg LTW. Road traffic accidents and psychotropic medication use in the Netherlands: a casecontrol study. Br J Clin Pharmacol [Internet]. 2011;72:505-13. Available from: http://doi.wiley.com/10.1111/j.1365-2125.2011.03994.x.

Sagberg F. Driver health and crash involvement: A case-control study. Accid Anal Prev. 2006;38(June 2005):28-34. Available from: https://www.ncbi.nlm.nih. gov/pubmed/16054104.

Sherwood N. Comparative behavioural toxicity of the selective serotonin reuptake inhibitors. Hum Psychopharmacol. 1995;10:S159-62.

Sims RV, McGwin G, Allman RM, Ball K, Owsley C. Exploratory study of incident vehicle crashes among older drivers. J Gerontol A Biol Sci Med Sci. 2000; 55(1):M22-7. Available from: http://www.ncbi.nlm.nih.gov/pubmed/10719769.

Wells G, Shea B, O'Connell D, Peterson J, Welch V, Losos M, et al. The NewcastleOttawa Scale (NOS) for assessing the quality of nonrandomised studies in meta-analyses. Ottawa Hosp Res Inst [Internet]. 2015. Available from. http:// www.ohri.ca/programs/clinical_epidemiology/oxford.asp.

Wickens CM, Mann RE, Stoduto G, lalomiteanu A, Smart RG, Rehm J. The impact of probable anxiety and mood disorder on self-reported collisions: A population study. J Affect Disord. 2013;145:253-5. Available from: http:// journals.Iww.com/intclinpsychopharm/abstract/1995/01004/the_behavioural_ toxicity_of_the_selective.2.aspx.

Zuin D, Ortiz H, Boromei D, Lopez OL. Motor vehicle crashes and abnormal driving behaviours in patients with dementia in Mendoza. Argentina Eur J Neurol. 2002:9:29-34. 